\title{
$\$$ Research Square \\ Explore the self-care needs in patients with cancer; a qualitative content analysis
}

\section{Fariba Mazhari}

Rafsanjan University of Medical Sciences

Zohreh Khoshnood ( $\sim$ khoshnood.tmu@gmail.com )

Kerman University of Medical Sciences

\section{Research article}

Keywords: Self-care, cancer, Iran, needs, qualitative study

Posted Date: April 2nd, 2020

DOI: https://doi.org/10.21203/rs.3.rs-20542/v1

License: (a) (i) This work is licensed under a Creative Commons Attribution 4.0 International License. Read Full License

Version of Record: A version of this preprint was published at BMC Nursing on August 9th, 2021. See the published version at https://doi.org/10.1186/s12912-021-00659-3. 


\section{Abstract}

Background : Cancer is one of the most critical health problems worldwide today. Studies by different researchers have shown that disease can reduce people's ability to self-care. Therefore, this study was conducted to investigate Self-care needs in patients with cancer.

Methods : This study is a conventional, qualitative content. Data saturation achieved after interviewing 13 participants in 15 interviews. With the in-depth semi-structured approach, the participants were asked to narrate their experiences of Self-care needs in the process of disease. The analysis was done according to Graneheim and Lundman's method, the following considered: the unit of analysis, meaning unit, condensation, code, subcategory, category, and main category.

Results : Data analysis leads to two main categories of the two main categories of "Deficiency in management of disease". Including three sub-categories: "the need to get rid of annoying physical symptoms"," Need for a caregiver in daily routine," and" Feeling frustrated and giving up treatment". The second main category of "the need for sympathetic and knowledgeable caregivers" with the following five sub-categories: "Need for sympathy and interaction with nurse", "the need to hear the truth about illness", " Need for appropriate therapeutic interaction from physicians", "Inadequate qualification of physicians' secretary about the patient", and" need for a psychologist for psychological adaptation. "

Conclusion : The most critical needs are compassionate and informed caregivers. So nursing management and care with kindness, competence, and conscience is the fundamental right of patients with cancer. Identifying the needs and problems of patients can be used as a background for increasing the knowledge and experience of nurses and providing care for patients with cancer.

\section{Background}

Cancer is one of the most critical health problems worldwide today(1). Cancer now accounts for $12 \%$ of deaths around the world and is expected to increase in the coming years, with an increase in the world's population and its average age, increased life expectancy, improved health status, and proper contagious disease control(2).

Cancer can reduce people's ability to do routine work, followed by feelings of depression, frustration, and other psychological problems (3-6). Boyes et al. (2012) also expressed that the highest level of support needs is in selfcare about physical needs and adaptation to illness in their own lives(7). In the study of Moghaddam et al. (2016), the most critical primary needs of patients with cancer were a deficiency in daily care, fatigue, pain, and the lack of advice from the treatment staff (8). Following this, self-care define as one of the most effective methods for controlling the physical and psychological effects $(6,9)$. According to Orem's definition, self-care can consider as covering all activities for the protection of life, health, and well-being (10). Therefore, it can state that self-care includes all activities that undertake for prevention, treatment, and increasing the quality of life, and satisfaction of the person with experience and rehabilitation (11).

By considering the experiences of patients, nursing care is one of the critical indicators in treatment and improving the quality of patient care (12), which largely depends on the quality of the communication with the patient (13). Therefore, from the perspective of patients with cancer, nurses have an essential role in knowing the self-care needs, and providing emotional and psychological care. So that counseling and support for people with 
cancer and their families at all stages of the disease must do, and patients should assure that they will receive the best care, and the patient will also be able to take care of himself (14). Thus, the importance of the ability of a patient with cancer in self-care and review of other studies shows that explore the self-care needs of patients, rehabilitation, and helping them with daily activities can make a significant contribution to reducing the psychological complications of the disease. Therefore, this study was conducted to explore the Self-care needs in patients with cancer through the qualitative study.

\section{Methods}

This study was a conventional qualitative content analysis with a descriptive explorative approach. The qualitative content analysis based on the unit of analysis. According to Graneheim and Lundman's method, the following concepts considered necessary: the unit of analysis, meaning unit, condensation, code, sub-category, category, and main category (15). Although the analysis process was systematic, it was a back-and-forth movement between the whole and parts of the text. Sampling continued until data were saturated, and no new information extract. In the present study, the saturation achieved after interviews with 13 participants in 15 meetings. Two participants were interviewed two times. For data saturation, patients, family members, and nurses with different and rich experience were invited to the interviews. Also, individuals with different characteristics such as age, role, and work experience were chosen by the second researcher to provide a wide range of information. On average, the participants had nine months to four years' experience of cancer. The mean age of participants was 45.7 years (table 1). Patients with cancer were interviewed from autumn 2016 to spring 2017. They referred to three hospitals affiliated ... for taking treatment services. A purposive sample of participants who had an experience of cancer participated in the research.

In-depth individual semi-structured interviews conducted with participants in their preferred time and place. The participants were asked to narrate their experiences of their self-care needs related to their disease. Clarifying and encouraging questions were used, such as 'Please, explain more about your self-care needs when your disease started?', 'What do you do when you feel the need for self-care?'; 'Can you provide an example'? The interviews were tape-recorded, transcribed verbatim, and analyzed by the first author. The interviews lasted between $40-110$ minutes.

This study was performed on humans, so the proposal of that introduced and approved in Kerman University of Medical Sciences Ethics committee to prevent any possible dangers on participants. Ethical Code:

IR.KMU.REC.1398.464. The researcher explained to the participants about the study and informed that they could withdraw at any time. They guaranteed as no names or facts were to state in data. Speaking about their needs and the experiences related to this subject has an emotionally charged nature and maybe a painful reminder of various situations. The researchers handled this risk by being attentive and sensitive to the interviewees' emotional reactions

\section{Trustworthiness}

Several techniques were used to enhance the reliability of the current study. The second researcher's supervisors have done peer checking. The research team tried to collect data from different people with different experiences and different socio-demographic characteristics. Through frequent sessions between the second researcher and the supervisors, the study's progress and process reported and discussed. Member checking completed with 
some of the participants for validation of interpreted findings. Some of the faculty members checked the encoding process and access to categories. Also, a clear and detailed description of the culture, context, selection, and characteristics of participants, data collection, and process of analysis provided.

This study was performed on humans, so the proposal of that introduced and approved in Kerman University of Medical Sciences Ethics committee to prevent any possible dangers on participants. Ethical Code:

IR.KMU.REC.1398.464. Written consent form was obtained from all participants of the study. The researcher explained to the participants about the study and informed that they could withdraw at any time. They guaranteed as no names or facts were to state in data. Speaking about their needs and the experiences related to this subject has an emotionally charged nature and maybe a painful reminder of various situations. The researchers handled this risk by being attentive and sensitive to the interviewees' emotional reactions

\section{Results}

Data analysis leads to the extraction of the two main categories include "Deficiency in management of disease" with three sub-categories. Another category is "The need for sympathetic and knowledgeable caregivers" with the five sub-categories.

\section{Deficiency in management of disease}

At the onset of cancer and symptoms of disease progression, patients faced with multiple physical difficulties. These physical complications considered as one of the basic needs of these patients. Patients felt unable to manage their symptoms and complications. In this regard, they expressed the need for help.

\section{Need to get rid of annoying physical symptoms}

Among the most critical problems that have been reported by patients were complications from chemotherapy. Patients were faced with many challenges to overcome these complications and found themselves close to death. During the chemotherapy process, patients had several experiences:

"Chemotherapy is like putting a bomb inside my body and then pressing its button. I have high pain tolerance, but when my white blood cells go down, I have a terrible condition. It's so painful. (P10)"

\section{Need for a caregiver in daily routine}

The majority of patients, after the onset of the disease and particularly during treatment, expressed their most crucial concern to do their daily routine, the fear of losing independence, the need for a caretaker to do their daily activities, and to fail to do things that they had done before.

"When I had chemotherapy and hospitalized, it was tough for me to pick up or move something and I needed someone to do it for me $(p)^{\prime \prime}$

"The side-effects after chemotherapy are considerable. The patient suffers from these complications, and because of that, he/she becomes overwhelmed and disabled. (P11 Oncology Nurse) "

\section{Feeling frustrated and giving up treatment}


At a stage where the patient is suffering from frequent hospitalizations, he becomes disconcerted and, when his treatment fails, he feels frustrated, and the possibility of a decision to give up the treatment increases.

"It's an unfortunate thing when his mood breaks down, and he says I'm not going to get well. I'll die. Who has recovered well from this illness? (P13 .mother of a patient)

\section{Need for sympathetic and knowledgeable caregivers}

According to the experiences of participants, this category included four sub-categories:

\section{Need for sympathy and interaction with a nurse}

Participants in this study mentioned empathy and the nurse-patient relationship as one of the main criteria for care. Some participants were satisfied with this relationship. They considered the treatment team as an essential factor in their treatment and recovery. However, some others thought this relationship and the competence and ability of nurses in oncology weak and mentioned the need for nursing education.

"Those times that I was eating my soup like a cat because I could not move my hands. The nurse said, Do you want me to put it in your mouth? I said no. She sat on the chair next to me. Suddenly I saw her crying. It was a good sense of empathy for me (P3)."

"New nurses should receive training, but that is no longer enough. Nurses need more expertise in practice. (P11 oncology nurse). "

\section{Need for hearing the truth about the disease}

According to patients' experiences, from the moment they diagnosed with the disease, thousands of ambiguous questions about the nature of the disorder come to mind, so they felt needed an informed person to clarify the issues in their minds. Some of the patients said that hearing the truth would help them to enter the stage of disease acceptance and fight their illness.

"I needed a person to explain to me what this disease was overall. How does this happen? Because this disease is like a giant, which creates fear and horror (P1)."

"The doctor told me, $0.7 \mathrm{~mm}$ of the tumor remained after the operation, and there is a significant danger. I liked her honesty because she did not hide my illness (p.8). "

\section{Need for appropriate therapeutic interaction from Physicians}

According to the results, it was essential to establish a productive therapeutic relationship between the doctor and the patient in the process of treatment. Many patients said that if a person diagnosed with cancer, he or she should first be mentally prepared.

"When I received my tests, the nurse said, "Madam, you have cancer, you need chemotherapy." As soon as she said this, I fell into a fit and collapsed. She didn't try to prepare my mind and then tell me (P 4). " 
One of the problems, as the participants stated, was the inappropriate behavior of Physicians' secretaries to the patients. Therefore, participants expressed that the oncologists' secretaries needed to be trained and informed about the psychological and physical condition of cancer patients.

"The secretaries should also be trained. They are so bad-tempered, and they want to fight. I even saw several times that they started fighting with the patients' companion (P10)."

\section{Need for a psychologist for psychological adaptation}

Since the onset of disease and the psychological crisis, patients may not have the ability to communicate appropriately and accept the condition. Therefore, the need for counseling by an informed person is essential. Unfortunately, there is currently no provision of psychological services in oncology departments, and this burden has imposed on nurses.

"We don't have psychoanalysts in our sections. There are some cases that the patient has a terrible psychological state and needs a psychologist (P12 oncology nurse)".

\section{Discussion}

Results showed cancer patients had many problems in the management of the disease and complications'. Studies by different researchers have shown that cancer can reduce people's ability to do routine work, followed by feelings of depression, frustration, and other psychological problems $(3-5,6674)$. As the results of Jansen's (2015), the overall patients' understanding of self-care is mostly related to physical self-care problems, need for counseling, the need for social care, the need for psychological care, and finding a solution to their life problems (16). In the studies by Moghaddam et al. (2016), O'Brien et al. (2017), and Boyes et al. (2012) reported that the most critical primary needs of patients with cancer were inability to do daily care, fatigue, pain, and the need for counseling with the staff treatment $(7,8,17)$

In this study, one of the cases deficiency in the management of disease was a feeling of frustration and needed to get rid of it in patients. In studies by Davis (2017), and Chu-Hui (2007), hope is one of the essential elements in the life of patients with cancer $(18,19)$. Several factors can help patients feel hopeful. Demographic characteristics of people, especially age and sex, mental status, social environment, spiritual or religious beliefs, symptoms and complications of the disease and previous experiences of the person may affect the level of hope and ability of the person to take care of themselves $(16,18,20-22)$. The studies by Davis (2017), Wahl (2004), Schjolberg (2011) and Jakobsson (2015) reported that there is a direct relationship between mental and physical problems, weakness, pain, and a sense of hope and well-being in patients with cancer $(18,22-24)$. According to various studies, this sense of confidence can increase by focusing on self-control, self-awareness, self-esteem, and a greater understanding of satisfaction with life $(22,25,26)$. According to the participant's statements, they have been able to more easily deal with the physical and emotional problems of the disease by focusing more on self-knowledge.

One of the patients' needs was to have access to a source for getting information on their illness. Stahl (2017) states that one of the least rights of the patients is the right of knowing and awareness. One of the essential duties of physicians is to promote patients' independence. So respect for the right to "know" is respect for patients' autonomy and authority. When patients receive accurate information about their illness and its 
prognosis, they can take realistic actions about self-care and disease management (27). Papadakos (2017), Giuliani et al. (2016), and Manne (2016) highlight the need for information in patients with cancer about physical care, medical information, and information to meet the emotional, social and spiritual needs (28-30). A systematic review by Moghaddam et al. (2016) has shown that four primary unmet needs in patients with cancer include a lack of awareness, concern, and uncertainty about the future of illness, fatigue, and deficiency in the management of disease (8).

One of the essential caring needs in this study is a deficiency in communication and the training of the patient by physicians, nurses, other members of the treatment team. Nursing care defined in four areas: physical, psychological, social, and spiritual. Therefore, nursing care is one of the critical factors in the treatment and improvement of care quality (12). This care depends on the quality of communication with the patient (13). For

providing quality of care not only psychological, functional, self-care, and financial needs be considered. Cooperation among the treatment team members, including the nurse and the patient, as well as home follow-up care, should also be considered (12)

Nurses must have the expertise, competence, knowledge of attitudes, and skills in providing care and support services to patients (14). The study by Nikbakht et al. (2003) and Makarem et al. (2016) stated that nursing care in Iran influenced by economic, social, political, and cultural issues (31, 32). In a study by Rafii et al. (2008), heavy workload and shortage of workforce and limitation of nurses' authority reduced the satisfaction of patients (33).

In the current study, one of the patients' needs is a deficiency in communication with physicians. Herd (2014) and Stefan (2010) reported that communicating with physicians and receiving clear answers from physicians as well as spiritual support by physicians plays a vital role in reducing anxiety and increasing patient satisfaction with care provision $(34,35)$. Contrary to the current study, in Makarem et al. (2016), the highest level of patient satisfaction with Physicians' actions (77.8\%) was an observance of ethical standards (76\%) (32). The difference between the results of the present study and the mentioned study can be because of the method. On the other hand, this difference can be due to differences in the provision of care and treatment and the therapeutic culture of physicians.

According to the participants' experiences in the current study, the lack of psychologists is one of the primary defects in the oncology wards. Unfortunately, in ... province, Patients' need for counseling has not been met, and patients are always involved with their psychological problems. In this regard, Jansen et al. (2015) and Moghaddam et al. (2016) also state that the primary need of patients with cancer was the need for counseling with the treatment team $(8,16)$.

\section{Conclusion}

The present study identified self-care needs in patients with cancer. The essential demands from the patient's included the requirements related to the management of the disease and the need to have caregivers. Concerned with the issues raised, patients need care with kindness, competence, and conscience, which is the fundamental right of patients with cancer and their families. One of the tasks of the treatment team is to strengthen the rehabilitation of these patients. The empowerment of them in self-care can reduce the complications of the disease. Nurses can estimate the needs of these patients and identify the factors that affect it, with the least cost 
and with a short period. Determining the needs and problems of patients can be used as a background for increasing the knowledge and experience of nurses and providing psychological, spiritual care, supportive counseling, and increasing the understanding of patients in their care.

\section{Declarations}

\section{Ethics approval and consent to participate}

This study was performed on humans, so the proposal of that introduced and approved in Kerman University of Medical Sciences Ethics committee to prevent any possible dangers on participants. Ethical Code:

IR.KMU.REC.1398.464. Written consent form was obtained from all participants of the study. The researcher explained to the participants about the study and informed that they could withdraw at any time. They guaranteed as no names or facts were to state in data. Speaking about their needs and the experiences related to this subject has an emotionally charged nature and maybe a painful reminder of various situations. The researchers handled this risk by being attentive and sensitive to the interviewees' emotional reactions

\section{Consent for publication}

All authors have approved the final article and acknowledge that all those entitled to authorship are listed as authors.

Authors Contributions: All authors have read and approved the manuscript.

\section{Availability of data and materials}

All of interview data are confidential based on giving consent form of participants.

\section{Funding}

No funding exist in this study.

\section{Authors' contributions}

Frist author: Data analysis, revise the article

Second author: the conception and design of the study, drafting the article, final approval of the version to be submitted.

\section{Acknowledgments}

The authors would like to acknowledge the ... University of Medical Sciences for supporting this work. Also, Special thanks to all participants who took part in this study.

\section{Competing interests}

Non-financial interests exist in this study.

\section{Abbreviations}


Not applicable.

\section{References}

1. Bonevski B, Sanson-Fisher R, Girgis A, Burton L, Cook P, Boyes A. Evaluation of an instrument to assess the needs of patients with cancer. Cancer. 2000;88(1):217-25.

2. Parkin DM, Bray F, Ferlay J, Pisani P. Global cancer statistics, 2002. CA: a cancer journal for clinicians. 2005;55(2):74-108.

3. Hong JS, Tian J. Prevalence of anxiety and depression and their risk factors in Chinese cancer patients. Supportive care in cancer. 2014;22(2):453-9.

4. Caruso R, GiuliaNanni M, Riba MB, Sabato S, Grassi L. Depressive Spectrum Disorders in Cancer: Diagnostic Issues and Intervention. A Critical Review. Current psychiatry reports. 2017;19(6):33.

5. Walker J, Sawhney A, Hansen CH, Ahmed S, Martin P, Symeonides S, et al. Treatment of depression in adults with cancer: a systematic review of randomized controlled trials. Psychological medicine. 2014;44(5):897907.

6. Goudarzian AH, Nesami MB, Zamani F, Nasiri A, Beik S. Relationship between depression and self-care in Iranian patients with cancer. Asian Pacific journal of cancer prevention: APJCP. 2017;18(1):101.

7. Boyes AW, Girgis A, D'Este C, Zucca AC. Prevalence and correlates of cancer survivors' supportive care need six months after diagnosis: a population-based cross-sectional study. BMC Cancer. 2012;12(1):1.

8. Moghaddam N, Coxon H, Nabarro S, Hardy B, Cox K. Unmet care needs in people living with advanced cancer: a systematic review. Supportive Care in Cancer. 2016;24(8):3609-22.

9. Bagherian B, Sabzevari S, Mirzaei T, Ravari A. Effects of technology on nursing care and caring attributes of a sample of Iranian critical care nurses. Intensive and Critical Care Nursing. 2017;39:18-27.

10. Weng LC, Dai YT, Wang YW, Huang HL, Chiang YJ. Effects of self-efficacy, self-care behaviours on depressive symptom of Taiwanese kidney transplant recipients. Journal of Clinical Nursing. 2008;17(13):1786-94.

11. Krebber A, Buffart L, Kleijn G, Riepma I, Bree R, Leemans C, et al. Prevalence of depression in cancer patients: a meta-analysis of diagnostic interviews and self-report instruments. Psycho-Oncology. 2014;23(2):121-30.

12. Litzelman K, Kent EE, Mollica M, Rowland JH. How does caregiver well-being relate to perceived quality of care in patients with cancer? Exploring associations and pathways. Journal of Clinical Oncology. 2016;34(29):3554.

13. Seccareccia D, Wentlandt K, Kevork N, Workentin K, Blacker S, Gagliese L, et al. communication and quality of care on palliative care units: a qualitative study. Journal of palliative medicine. 2015;18(9):758-64.

14. Liu JE, Mok E, Wong T. Caring in nursing: investigating the meaning of caring from the perspective of cancer patients in Beijing, China. Journal of Clinical Nursing. 2006;15(2):188-96.

15. Graneheim UH, Lundman B. Qualitative content analysis in nursing research: concepts, procedures and measures to achieve trustworthiness. Nurse education today. 2004;24(2):105-12.

16. Jansen F, van Uden-Kraan CF, van Zwieten V, Witte BI, Verdonck-de Leeuw IM. Cancer survivors' perceived need for supportive care and their attitude towards self-management and eHealth. Supportive Care in Cancer. 2015;23(6):1679-88. 
17. O'Brien KM, Timmons A, Butow P, Gooberman-Hill R, O'Sullivan E, Balfe M, et al. Associations between neighbourhood support and financial burden with unmet needs of head and neck cancer survivors. Oral oncology. 2017;65:57-64.

18. Davis MP, Lagman R, Parala A, Patel C, Sanford T, Fielding F, et al. Hope, Symptoms, and Palliative Care: Do Symptoms Influence Hope? American Journal of Hospice and Palliative Medicine®. 2017;34(3):223-32.

19. Chu-Hui-Lin Chi G, editor The role of hope in patients with cancer. Oncology Nursing Forum; 2007.

20. Parker PD, Ciarrochi J, Heaven P, Marshall S, Sahdra B, Kiuru N. Hope, friends, and subjective well-being: A social network approach to peer group contextual effects. Child Development. 2015;86(2):642-50.

21. Nadi MA, Ghahremani N. The relationship between dimensions of religiosity/spirituality with mental health and hope for future between staff of public hospitals in Shiraz. Journal of education and health promotion. $2014 ; 3$.

22. Jakobsson S, Ekman T, Ahlberg K. Living through pelvic radiotherapy: A mixed method study of self-care activities and distressful symptoms. European Journal of Oncology Nursing. 2015;19(3):301-9.

23. Schjolberg TK, Dodd M, Henriksen N, Rustoen T. Factors affecting hope in a sample of fatigued breast cancer outpatients. Palliative \& supportive care. 2011;9(1):63-72.

24. Wahl AK, Rustøen T, Lerdal A, Hanestad BR, KNUDSEN JR Ø, Moum T. The Norwegian version of the Herth Hope Index (HHI-N): a psychometric study. Palliative \& supportive care. 2004;2(3):255-63.

25. Rawdin B, Evans C, Rabow MW. The relationships among hope, pain, psychological distress, and spiritual well-being in oncology outpatients. Journal of palliative medicine. 2013;16(2):167-72.

26. Wnuk M, Marcinkowski JT, Fobair P. The relationship of purpose in life and hope in shaping happiness among patients with cancer in Poland. Journal of Psychosocial Oncology. 2012;30(4):461-83.

27. Stahl D, Tomlinson T. Is there a right not to know? Nature Reviews Clinical Oncology. 2017;14(5):259.

28. Papadakos J, McQuestion M, Gokhale A, Damji A, Trang A, Abdelmutti N, et al. Informational Needs of Head and Neck Cancer Patients. Journal of Cancer Education. 2017:1-10.

29. Giuliani M, McQuestion M, Jones J, Papadakos J, Le LW, Alkazaz N, et al. Prevalence and nature of survivorship needs in patients with head and neck cancer. Head \& neck. 2016;38(7):1097-103.

30. Manne S, Hudson SV, Baredes S, Stroup A, Virtue SM, Paddock L, et al. Survivorship care experiences, information, and support needs of patients with oral and oropharyngeal cancer. Head \& neck. 2016;38(S1).

31. Nikbakht Nasrabadi A, Parsa Yekta Z, Seif H, Rasoolzadeh N. Professionalization experiences of newly employed nurses in clinical settings in Iran. Hayat. 2005;11(4):5-18.

32. Makarem J, Larijani B, Joodaki K, Ghaderi S, Nayeri F, Mohammadpoor M. Patients' satisfaction with inpatient services provided in hospitals affiliated to Tehran University of Medical Sciences, Iran, during 20112013. Journal of medical ethics and history of medicine. 2016;9.

33. Rafii F, Hajinezhad ME, Haghani H. Nurse caring in Iran and its relationship with patient satisfaction. Australian Journal of Advanced Nursing, The. 2008;26(2):75.

34. Herd HA, Rieben MA. Establishing the surgical nurse liaison role to improve patient and family member communication. AORN journal. 2014;99(5):594-9.

35. Stefan KA. The nurse liaison in perioperative services: a family-centered approach. Aorn journal. 2010;92(2):150-7. 
Tables

Table 1- characteristic of participants

\begin{tabular}{|c|c|c|c|c|}
\hline Participant's code & Age & Gender & Cancer type & Marital status \\
\hline 1 & 34 & Male & Leukemia & Single \\
\hline 2 & 47 & Female & Breast & Married \\
\hline 3 & 29 & Male & Leukemia & Single \\
\hline 4 & 55 & Female & Breast & Married \\
\hline 5 & 44 & Female & Breast & Married \\
\hline 6 & 40 & Female & Breast & Divorced \\
\hline 7 & 70 & Male & Colon & Married \\
\hline 8 & 56 & Female & Breast & Married \\
\hline 9 & 37 & Female & Pancreatic & Married \\
\hline 10 & 45 & female & Non-Hodgkin's Lymphoma & Married \\
\hline 11 & 38 & female & Nurse with 9 years' work experience in the oncology ward & Married \\
\hline 12 & 34 & female & Nurse with 10 years' work experience in the oncology ward & Married \\
\hline 13 & 37 & female & Mother of a patient with Leukemia & Married \\
\hline
\end{tabular}

Page 11/11 